\title{
Divergent selection on feather pecking behaviour in laying hens (Gallus gallus domesticus)
}

\author{
J.B. Kjaer ${ }^{\mathrm{a}, *, 1}$, P. Sørensen ${ }^{\mathrm{b}}$, G. Su${ }^{\mathrm{b}}$ \\ ${ }^{a}$ Department of Animal Health and Welfare, Danish Institute of Agricultural Sciences, \\ P.O. Box 50, Foulum, DK-8830 Tjele, Denmark \\ ${ }^{\mathrm{b}}$ Department of Animal Breeding and Genetics, Danish Institute of Agricultural Sciences, \\ P.O. Box 50, Foulum, DK-8830 Tjele, Denmark
}

Accepted 28 August 2000

\begin{abstract}
A selection experiment was initiated in 1996 in which selection for (HP line) and against (LP line) feather pecking was performed. The foundation stock was a White Leghorn layer strain established in 1970 and maintained since then as a random bred control line at the Institute. Six hatches were produced over three generations. At the age of 68 weeks (generation 0, 1996), 35 weeks (generation 1, 1997), 30 weeks (generation 2, 1998), and 27 weeks (generation 3, 1999) female birds were transferred to observation pens and their feather pecking behaviour was recorded. In each generation, 30 females and 8 males were selected from approximately 200 females and 60 males. The selection criterion was breeding value estimated by animal model on the trait 'number of bouts of feather pecking per bird per hour'.

Feather pecking behaviour in adult hens was significantly higher in HP than in LP. In generation 2 the following was recorded: 3.10 versus 1.37 bouts per bird per hour $(P<0.01), 7.04$ versus 3.58 pecks per bird per hour $(P<0.05)$ and the proportion of hens recorded feather pecking in the $180 \mathrm{~min}$ observation period was 67 versus 56\% $(P<0.05)$. In generation 3 the following was recorded: 4.56 versus 0.63 bouts per bird per hour $(P<0.001), 13.9$ versus 2.51 pecks per bird per hour $(P<0.001)$ and the proportion of hens recorded feather pecking in the $180 \mathrm{~min}$ observation period was 75 versus $49 \%(P<0.001)$.

In generation 3, plumage condition was better in LP on neck, breast, back, wings and tail, as well as overall $(P<0.001)$. Body weight did not differ between lines in generation 2 , but in generation 3, HP hens were on average heavier than LP hens at the age of 27 weeks (1435 g versus $1371 \mathrm{~g}$, $P<0.001)$. (C) 2001 Elsevier Science B.V. All rights reserved.
\end{abstract}

Keywords: Chicken-anomalous behaviour; Feather pecking behaviour; Selection; Aggression; Animal welfare

\footnotetext{
* Corresponding author. Tel.: +45-89-99-19-00; fax: +45-89-99-15-00.

E-mail address: j.kjaer@agrsci.dk (J.B. Kjaer).

${ }^{1}$ Homepage Research Centre Foulum: http://www.agrsci.dk.
} 


\section{Introduction}

Feather pecking is characterised as non-aggressive pecks (Hoffmeyer, 1969) directed towards the plumage of other birds and it has been shown to be the main reason for deterioration of the plumage of laying hens housed in a range of production systems (Hughes, 1985; Appleby et al., 1988; Nørgaard-Nielsen et al., 1993). Some authors have reported two types of feather pecking, namely severe pecking, responsible for the feather damage, and gentle pecking resembling a stereotypy (Kjaer and Vestergaard, 1999). The more extreme cases of these two types of feather pecking are clearly distinguishable, but a range in severity does exist and the classification is more or less subjective. When skin or muscle is damaged, this is called cannibalism and can be regarded as a final phase of (severe) feather pecking (Blokhuis and Arkes, 1984). Cannibalism can also occur without previous feather pecking. This is referred to as 'vent-pecking' (Hughes and Duncan, 1972; Allen and Perry, 1975).

A number of studies have demonstrated strain differences in the amounts of damage to the integument (Craig and Lee, 1990; Blokhuis and Beutler, 1992; Kjaer, 1995). Estimation of genetic variation in feather pecking behaviour based on direct observation of pecking behaviour has only been reported by a few authors (Cuthbertson, 1980; Bessei, 1984; Kjaer and Sørensen, 1997). Heritability estimates of feather pecking range from 0.05 to 0.56 depending on the variable used and the age of the chickens. Craig and Muir (1993) studied the genetics of the different, but related, behaviour cannibalism. These authors demonstrated the possibility of selecting against 'beak inflicted injuries' and estimated realised family heritability for cannibalistic behaviour to be $0.65 \pm 0.13$.

The objectives of the on-going selection experiment are to test the general assumption that feather pecking is a heritable trait, and more specifically the results found by Kjaer and Sørensen (1997), that feather pecking has a moderate heritability and might be changed by selection. This paper describes the design and method of selection and presents results of feather pecking and aggressive behaviour, plumage condition and body weight of adult birds during three generations of selection.

\section{Material and methods}

\subsection{Foundation stock}

The foundation stock was chosen to be a White Leghorn layer strain established in 1970 as a control population in the Scandinavian selection and cross breeding experiment (Liljedahl et al., 1979) and maintained since then as a random bred line at the Institute.

\subsection{Rearing procedures}

Six hatches were produced over three generations. Chickens were reared in floor pens in environment controlled houses with a temperature of $34^{\circ} \mathrm{C}$ at day old gradually decreasing 
to $20^{\circ} \mathrm{C}$ at 8 th week. Each pen was equipped with round feed troughs and round drinkers. The floor was covered with a $5 \mathrm{~cm}$ deep layer of wood shavings at the start of the experiment. At 18th week pullets were transferred to four-bird battery cages in two levels and males were transferred to single cages. Standard poultry mash and water were provided ad libitum during the whole experiment. The feed had a crude protein content of 20.5, 13.2 and $16.4 \%$ and an energy content (MJME/kg fresh) of $11.6,11.9$ and 11.1 from 0 to 5 weeks, 6 to 15 weeks and 16 weeks to end of lay, respectively. In the floor pens, lines were mixed to avoid effects of the environment. In cages, lines were kept separate (LP or HP birds in a cage), but LP and HP cages were balanced over rows (1,2), levels (up, down) and length of the house.

\subsection{Behavioural testing procedures}

At the age of about 67 weeks (generation 0, 1996), 34 weeks (generation 1, 1997), 29 weeks (generation 2, 1998) and 26 weeks (generation 3, 1999) all female birds were transferred to observation pens. Each pen measured $2 \mathrm{~m} \times 4 \mathrm{~m}$ and held a group of 20 hens. For individual identification birds were tagged in each wing with a $12 \mathrm{~g}$ plastic tag (originally ear tags for cows; All Flex, DK-7620 Lemvig, Denmark). After a period of 7-12 days (settling in) their behaviour was recorded by video (Panasonic WV-BL200 camera, WV-LA4510E lens, and AG-6720 recorder) at natural speed. Incandescent light gave a light intensity of about $25 \mathrm{~lx}$ at ground level. Feed and water were given ad libitum during the observation hours. Videotapes were analysed at natural speed and all interactions involving beak contact were recorded. Each group was observed for 180 min (120 min for generation 0). All pecks at other chickens were recorded. Each peck was counted, and these were recorded in groups (events), in the following called bouts, rather than in single pecks. A bout was defined as pecks in a continuous series directed to the same chicken to the same body part (see below). The inter bout interval was 5-10 s depending on the actual situation (disturbance, change of target bird or target part of body, etc.). For every bout the following was recorded: identification of performer, identification of receiver, the number of peck(s) and classification of pecks as aggressive or non-aggressive. The distinction between non-aggressive and aggressive pecks was in most cases quite clear, aggressive pecks being vigorous, directed towards the head region and forcing the receiver to react (escape or fight) (Hoffmeyer, 1969; Wennrich, 1975). The trait used for selection was based on "number of bouts performed" in order to avoid hens doing gentle pecking (with many pecks per bout) being selected in the high pecking line in favour of hens doing mostly severe pecking (see below). In this way the selection was expected to change the relative proportion of pecks of the two types towards more severe pecking. In the pecking data from generation 2 presented here, non-aggressive pecks to feathers were classified as gentle pecks if the number of pecks per bout was 10 or larger and gentle pecks were analysed separately. The method of classifying severity of feather pecking by the number of pecks per bout was used in order to make the classification as objective as possible. The threshold of 10 pecks per bout was based on preliminary observations of bout length of subjectively classified gentle and severe feather pecking in earlier studies. Severe feather pecking usually made the recipient withdraw or react aggressively in these studies. 


\subsection{Selection procedures}

The 123 hens from the random bred control line of generation 1995 at the Research Centre Foulum were, at the age of 68 weeks, assessed for feather pecking activity. This information was used to estimate a breeding value for the hens and their 25 full brothers. The breeding value of a bird is the genetically based improvement the offspring is expected to have compared to offspring from randomly chosen parents. Breeding values depend on a combination of own performance (if available) and performance of relatives, and the heritability of the trait in question. The trait chosen for selection throughout the experiment was number of bouts of feather pecking. Among the 123 hens of the control line the 30 females and 10 males with the lowest breeding values were selected as parents for the generation 1 of the low pecking line (LP). The 30 females and 10 males with the highest breeding values were selected for the high pecking line (HP).

From generation 1 and onwards the two experimental lines were kept without migration of genes except in generation 1 in which an error in handling of the male chickens of the two lines made it necessary to use males from the control line. The procedure in selection was similar for the following generations, and is summarised in Table 1.

For generation 0 the family-index (Liljedahl et al., 1979) was used to estimate the breeding values while an animal model was used in the following three generations.

\subsubsection{Observations on generation 2}

Condition of plumage and body weight of all hens were recorded at 29th week, at the time when the birds were housed in cages, one cage holding birds from one line only. The condition of plumage was assessed according to Tauson et al. (1984) using an integer score of $1-4$, where 4 meant no damage and 1 a very poor condition. Plumage condition was scored separately on the neck, breast, back, wings and tail. The five scores were added together to give a total score ranging from 5 to 20 points.

\subsubsection{Observations on generation 3}

Condition of plumage and body weight of all hens were recorded at 26th week, using the method described above (observations on generation 2).

Table 1

Overview of number of birds per line raised to the time of assessment, numbers selected as breeding birds, age at assessment of feather pecking and methods used in estimating breeding values

\begin{tabular}{|c|c|c|c|c|c|c|c|c|}
\hline & \multicolumn{2}{|l|}{0} & \multicolumn{2}{|l|}{1} & \multicolumn{2}{|l|}{2} & \multicolumn{2}{|l|}{3} \\
\hline & $\mathrm{LP}$ & $\mathrm{HP}$ & LP & $\mathrm{HP}$ & LP & $\mathrm{HP}$ & LP & $\mathrm{HP}$ \\
\hline Age at assessing (weeks) & 68 & 68 & 35 & 35 & 29 & 29 & 27 & 27 \\
\hline No. of females assessed & 123 & 123 & 193 & 191 & 260 & 225 & 187 & 212 \\
\hline No. of males raised & 25 & 25 & 54 & 54 & 58 & 51 & 52 & 59 \\
\hline No. of females selected & 30 & 30 & 30 & 30 & 30 & 30 & 30 & 30 \\
\hline No. of males selected & 10 & 10 & 8 & 8 & 8 & 8 & 8 & 8 \\
\hline Methods used & \multicolumn{2}{|c|}{$\begin{array}{l}\text { Family } \\
\text { index }\end{array}$} & \multicolumn{2}{|c|}{$\begin{array}{l}\text { Animal } \\
\text { model }\end{array}$} & \multicolumn{2}{|c|}{$\begin{array}{l}\text { Animal } \\
\text { model }\end{array}$} & \multicolumn{2}{|c|}{$\begin{array}{l}\text { Animal } \\
\text { model }\end{array}$} \\
\hline
\end{tabular}




\subsection{Reproduction}

The selected parents were placed in individual cages and a male was dedicated to three or four females. The fertility of the eggs was ensured by artificial insemination twice a week during the period of collecting eggs for hatching. For each generation two hatches were produced, each of them with eggs from a 3-week period. The hatch was carried out with full pedigree and the newly hatched chicks were tagged with numbered wing bands identifying the parents.

\subsection{Statistical analysis}

Data on pecking behaviour in generations 2 and 3 adult hens was tested using the paired difference $t$-test (normally distributed pecking rates) or Wilcoxon signed rank test (nonnormally distributed proportions), with 22 mixed-line groups as statistical units in each generation. Hens were randomly (within line) allocated to groups holding on average 20 hens (10 hens from each selection line) during recording of pecking behaviour.

The breeding value for each individual male and female was estimated by using animal model (Henderson, 1984). The relationship matrix included all birds contributing to the particular line from the parents of the base generation to the actual generation. The analysis was accomplished using a restricted maximum likelihood (REML) procedure by means of the DMU package (Jensen and Madsen, 1993). A feature of this procedure is that it implicitly makes an estimate of the heritability for the trait selected for.

Plumage condition was analysed by non-parametric Kruskal-Wallis test (chi-square approximation). Cage means were used as statistical units. Body weight was analysed by analysis of variance with individual records as statistical units. The model included cage row $(1,2)$, cage level $(1,2)$ and hatch $(1,2)$. SAS software was used for the calculations (SAS Institute Inc., 1994).

\section{Results}

\subsection{Feather pecking behaviour}

Feather pecking behaviour in generations 2 and 3 adult hens was significantly higher in HP than in LP in all measures: bouts per bird per hour, pecks per bird per hour and proportion of hens recorded feather pecking in a $3 \mathrm{~h}$ observation period (Tables 2 and 3 ). In Fig. 1, results of the feather pecking rates (bouts per bird per hour) of the founder line hens in generation 0 , as well as the experimental lines generation 1-3 are shown.

Gentle feather pecking differed in the same way as total feather pecking, even though neither the number of gentle pecks nor the proportion of hens recorded performing gentle feather pecking differed significantly between selection lines in generation 2 (Tables 2 and 3 ). The average frequency (calculation based on 22 pen means per generation) of birds recorded performing gentle feather pecking was only 10 and $18 \%$ in generations 2 and 3, respectively. The frequency of gentle pecking seems to be more susceptible to environmental factors than severe pecking (Kjaer and Vestergaard, 1999). 
Table 2

Pecking activity (average no. of pecks per bird per hour) in adult hens of generations 2 and 3

\begin{tabular}{|c|c|c|c|c|c|c|c|c|c|c|}
\hline & \multicolumn{5}{|l|}{ Bouts } & \multicolumn{5}{|l|}{ Pecks } \\
\hline & \multicolumn{2}{|l|}{ LP } & \multicolumn{3}{|l|}{ HP } & \multicolumn{2}{|l|}{ LP } & \multicolumn{3}{|l|}{ HP } \\
\hline & Mean & S.E.M. & Mean & S.E.M. & $P<$ & Mean & S.E.M. & Mean & S.E.M. & $P<$ \\
\hline \multicolumn{11}{|l|}{ Generation 2} \\
\hline \multicolumn{11}{|l|}{ Feather pecking } \\
\hline Total & 1.37 & 0.30 & 3.10 & 0.45 & 0.010 & 3.58 & 0.78 & 7.04 & 1.04 & 0.050 \\
\hline Gentle & 0.04 & 0.02 & 0.09 & 0.02 & 0.050 & 1.13 & 0.45 & 2.11 & 0.72 & ns \\
\hline Aggressive pecking & 0.68 & 0.09 & 0.53 & 0.05 & ns & 0.73 & 0.10 & 0.60 & 0.05 & ns \\
\hline \multicolumn{11}{|l|}{ Generation 3} \\
\hline \multicolumn{11}{|l|}{ Feather pecking } \\
\hline Total & 0.63 & 0.11 & 4.56 & 0.82 & 0.001 & 2.51 & 0.62 & 13.9 & 1.81 & 0.001 \\
\hline Gentle & 0.05 & 0.02 & 0.28 & 0.04 & 0.001 & 0.87 & 0.37 & 4.94 & 0.80 & 0.001 \\
\hline Aggressive pecking & 0.57 & 0.05 & 0.54 & 0.04 & ns & 0.64 & 0.06 & 0.60 & 0.05 & ns \\
\hline
\end{tabular}

The bout length of total feather pecking was 2.4 and 3.5 pecks per bout, respectively, in generations 2 and 3, and it did not differ significantly between lines in any year. During estimation of breeding values in generation 3 the estimate of heritability was found to be 0.199 .

\subsection{Aggressive behaviour}

Aggressive pecking did not differ significantly between lines in neither generation, as can be seen from Table 2 . There was a tendency to more aggressive bouts in LP ( 0.68 versus 0.53 bouts per bird per hour, $P=0.0699$ ) in generation 2 . In generation 3 on average 0.56 aggressive bouts and 0.62 aggressive pecks per bird per hour were recorded.

Table 3

Proportion of birds recorded pecking at least once during a 180 min observation period (\%)

\begin{tabular}{|c|c|c|c|c|c|}
\hline & \multicolumn{3}{|c|}{ Mean of proportion } & \multicolumn{2}{|c|}{ Range of proportion ${ }^{\mathrm{a}}$} \\
\hline & LP & HP & $P<<^{\mathrm{b}}$ & LP (low-high) & HP (low-high) \\
\hline \multicolumn{6}{|l|}{ Generation 2} \\
\hline \multicolumn{6}{|l|}{ Feather pecking } \\
\hline Total & 56 & 67 & 0.050 & $29-75$ & $33-100$ \\
\hline Gentle & 7 & 13 & ns & $7-50$ & $8-50$ \\
\hline Aggressive pecking & 66 & 55 & ns & $25-93$ & $8-80$ \\
\hline \multicolumn{6}{|l|}{ Generation 3} \\
\hline \multicolumn{6}{|l|}{ Feather pecking } \\
\hline Total & 49 & 75 & 0.001 & $22-80$ & $50-100$ \\
\hline Gentle & 9 & 26 & 0.050 & $9-30$ & $10-50$ \\
\hline Aggressive pecking & 55 & 52 & ns & $17-90$ & $22-75$ \\
\hline
\end{tabular}

${ }^{a}$ Proportion range: highest and lowest proportion of hens recorded pecking in 22 pens.

${ }^{\mathrm{b}}$ Wilcoxon signed rank test, $N=22$. 


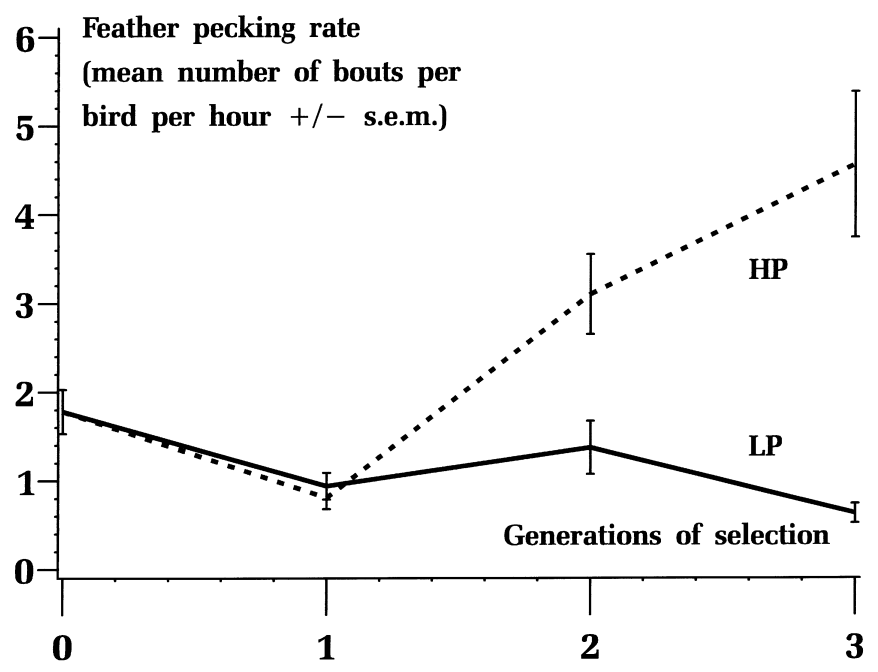

Fig. 1. Feather pecking rate (mean number of bouts per bird per hour + S.E.M.) of founder White Leghorn line in generation $P$ (corresponding to generation 0) and selection lines LP and HP in generations 1-3.

The number of aggressive pecks per bout was on average 1.10 and 1.12 in generations 2 and 3, respectively, not significantly different between lines. The proportion of birds recorded pecking aggressively did not differ between lines and was on average $61 \%$ in generation 2 and $54 \%$ in generation 3 .

\subsection{Plumage condition and body weight}

In the second generation, plumage condition on the wings was significantly better in LP. But there was a line by hatch interaction effect, so when lines were compared by hatch, a significantly better total feather score of LP was found in hatch 1 (17.5 p versus $16.6 \mathrm{p}$,

Table 4

Condition of plumage and body weight of generations 2 (hatch 1) and 3 (hatch 1 and 2) adult hens

\begin{tabular}{|c|c|c|c|c|c|c|}
\hline & \multicolumn{3}{|l|}{2} & \multicolumn{3}{|l|}{3} \\
\hline & LP & $\mathrm{HP}$ & $P<$ & LP & HP & $P<$ \\
\hline \multicolumn{7}{|c|}{ Plumage, points } \\
\hline Total $^{\mathrm{a}}$ & 17.5 & 17.3 & ns & 19.7 & 18.5 & 0.001 \\
\hline $\mathrm{Neck}^{\mathrm{b}}$ & 3.84 & 3.74 & ns & 3.93 & 3.74 & 0.001 \\
\hline Breast $^{\mathrm{b}}$ & 3.73 & 3.52 & ns & 3.89 & 3.49 & 0.001 \\
\hline Back $^{\mathrm{b}}$ & 3.42 & 3.20 & ns & 3.92 & 3.54 & 0.001 \\
\hline Wings ${ }^{b}$ & 3.47 & 3.23 & 0.01 & 4.00 & 3.95 & 0.01 \\
\hline Tail $^{\text {b }}$ & 2.96 & 2.89 & $\mathrm{~ns}$ & 3.99 & 3.77 & 0.001 \\
\hline Body weight & 1459 & 1485 & ns & 1371 & 1435 & 0.001 \\
\hline
\end{tabular}

${ }^{\text {a }}$ Sum of scores for the five body parts, where $20=$ nearly $100 \%$ coverage, $5=$ nearly no coverage.

${ }^{\mathrm{b}}$ Scores $1-4$, where $4=$ nearly $100 \%$ coverage, $1=$ nearly no coverage. 
$P<0.01)$. Better plumage condition on breasts was found in LP in hatch 1 (3.76 p versus $3.52 \mathrm{p}, P<0.01$ ), but the opposite, better plumage condition on breasts in HP was found in hatch 2 (3.88 p versus $3.55 \mathrm{p}, P<0.05)$. Hatch 1 included data from 96 cages, hatch 2 from only 33 cages. In generation 3 , a much clearer picture was seen. Plumage condition, in total as well as for each distinct body part, was significantly better in LP (Table 4).

Body weight tended to be higher in HP in generation 2 (Table 4). Birds were heavier in hatch 1 (1494 g versus $1450 \mathrm{~g}, P<0.01)$. In generation 3 results were clearer cut. HP hens were heavier $(1435 \mathrm{~g}$ versus $1371 \mathrm{~g}, P<0.001)$ and birds from hatch 1 were on average heavier than birds from hatch $2(1422 \mathrm{~g}$ versus $1324 \mathrm{~g}, P<0.05)$. Only few hens had scars or wounds on the skin, feet or comb, and no further calculations were made on these data.

\section{Discussion}

Selection was obviously effective in changing feather pecking behaviour, and this is also manifested through the estimated value of 0.2 for the realised heritability that expresses the average genetic changes in the two experimental lines. This is also underlined by the fact that twice as much feather pecking was recorded in HP compared to LP in generation 2 and up to seven-folds more in generation 3. This result verifies the work of Kjaer and Sørensen (1997), who estimated heritability of performing feather pecking in White Leghorn layers to $0.13 \pm 0.07$ at 38 th week and $0.35 \pm 0.12$ at 69 th week, and concluded that selection would be feasible in changing feather pecking behaviour.

A glance at Fig. 1 reveals an asymmetric response with a coefficient of regression of feather pecking bouts on generations of 0.3 for line LP and of 1.0 for line HP. Theoretically, LP will respond less if selection is effective, and the level of feather pecking falls under a certain threshold, at which most birds do not show any feather pecking (Bessei, 1995). Also the scaling factor contributes to the asymmetric response. From Fig. 1 it is seen that the SEM is much less for the LP line compared to the HP line. The consequences are that the expected genetic changes will be correspondingly smaller even with the same degree of inheritance. Thus, although the heritability for numbers of bouts is the same in the two lines, the resulting response to divergent selection might well be asymmetric.

No effect of selection on the amount of aggressive behaviour was found. This is in agreement with Hoffmeyer (1969) and Blokhuis and Arkes (1984), who did not find any relation between dominance and pecking at conspecifics. Hughes and Duncan (1972) found a weak relation between dominance rank in cages and pecking damage but concluded: 'the association between the tendency to feather peck and social dominance is not an absolute one'.

As could be expected from the pecking data, plumage condition was superior in LP birds. Numerous authors (see Section 1) have reported strain differences in plumage condition in cage layers. Change in the level of feather damage in layer lines after specific selection on feather pecking behaviour has not been reported earlier.

Only few selection experiments on traits related to feather pecking have been reported. Selection of family groups, in a Rhode Island layer strain, showing extremely high or low feather pecking rates, produced significant differences in the offspring (Bessei et al., 1999). Keeling and Wilhelmson (1997) selected Hisex Brown medium heavy layers for 2 
generations. From a base population of 70 hens, eight high feather peckers and eight low feather peckers were selected and reproduced. Their progeny differed in feather pecking behaviour. Only eight birds from the low pecking line showed feather pecking, while 12 birds of the high pecking line were recorded feather pecking. However, in the second generation, there was no difference in the feather pecking rate. The second generation was deliberately inbred (half brother mated to his half sister) and this resulted in a very low hatchability and only 15 birds for behavioural observations. The study of Craig and Muir (1993) was much larger and more successful. These authors demonstrated the possibility of selecting against 'beak inflicted injuries'. The main reason for injuries was expected to be cannibalism, but aggression might very well have been a part of the trait, too. One type of cannibalism can be regarded as a final phase of severe feather pecking (McKeegan and Savory, 1999). Another type is the so-called cloacal cannibalism, and this is quite unrelated to feather pecking (Allen and Perry, 1975). The way of recording cannibalism and feather pecking differs. Craig and Muir (1993) recorded the number of days passing without injuries or death, while kept in 9-12 bird cages in family groups at very high stocking densities, while in the present study, we recorded feather pecking behaviour in floor pens at a relatively low stocking density $\left(2.5\right.$ birds per $\left.\mathrm{m}^{2}\right)$ in mixed groups of LP and HP birds.

Body weight was in the present study positively correlated to feather pecking behaviour. This is in contrast to earlier findings (Kjaer and Sørensen, 1997). According to these authors, a smaller body weight could be expected in the HP line. Further experiments are needed to draw firmer conclusions on this question, but results from selection experiments, as presented here, are in general more reliable than estimates based on results from one single generation.

In conclusion, the present study is the first to present data on laying hens selected for and against feather pecking behaviour for three generations in out-bred lines. Feather pecking behaviour was changed by three generations of direct selection, while selection did not affect aggressive behaviour. This change in feather pecking behaviour resulted in significant changes of plumage condition. It is still to be shown if feather pecking can be reduced by genetic selection, but the data presented here, supports this suggestion. This would alleviate the welfare problems following feather pecking in a wide range of egg production systems. Especially in loose housing systems (aviaries, free range), where environmental control is limited, control of feather pecking will be of major benefit to the hens as well as production economy.

\section{Acknowledgements}

This experiment was financially supported by the Danish Ministry of Food, Agriculture and Fisheries. The authors wish to thank the following persons. Birte Lindstrøm Nielsen and Margit Bak Jensen gave valuable comments on earlier versions of this manuscript. Karin V. Østergaard and Ellen Fritze corrected the English language. Jørg Bonnichsen and co-workers took excellent care of the birds. Per K. Isaksen was in charge of the behavioural recordings. A special thank goes to Werner Bessei and the people at University of Hohenheim for fruitful discussions and very valuable co-operation as well as Christine 


\section{Nicol and Melissa Albentosa, University of Bristol, who are doing detailed behavioural studies on generation 3 chickens.}

\section{References}

Allen, J., Perry, G.C., 1975. Feather pecking and cannibalism in a caged layer flock. Poult. Sci. 16, 441-451. Appleby, M.C., Hogarth, G.S., Anderson, J.A., Hughes, B.O., Whittemore, C.T., 1988. Performance of a deep litter system for egg production. Br. Poult. Sci. 29, 735-751.

Bessei, W., 1984. Untersuchungen zur Heritabilität des Federpickverhaltens bei Junghennen. I. Mitteilung. Arch. Geflügelk. 48, 224-231.

Bessei, W., 1995. Genetics of feather pecking. In: Sørensen, P. (Ed.), Proceedings of the 2nd European Poultry Breeders Roundtable, 6-8 September. Research Centre Foulum, Report no. 73 from the Danish Institute of Agricultural Sciences, P.O. Box 50, DK-8830 Tjele, pp. 9-22 (in Danish with English summary).

Bessei, W., Reiter, K., Bley, T., Zeep, F., 1999. Measuring pecking of a bunch of feathers in individually housed hens: first results of genetic studies and feeding related reactions. Lohmann Inform. 22, 27-31.

Blokhuis, H.J., Arkes, J.G., 1984. Some observations on the development of feather pecking in poultry. Appl. Anim. Behav. Sci. 12, 145-157.

Blokhuis, H.J., Beutler, A., 1992. Feather pecking damage and tonic immobility response in two lines of White Leghorn hens. J. Anim. Sci. 70, 170.

Craig, J.V., Lee, H.Y., 1990. Beak trimming and genetic stock effects on behaviour and mortality from cannibalism in white leghorn-type pullets. Appl. Anim. Behav. Sci. 25, 107-123.

Craig, J.V., Muir, W.M., 1993. Selection for reduction of beak-inflicted injuries among caged hens. Poult. Sci. $72,411-420$.

Cuthbertson, G.J., 1980. Genetic variation in feather pecking behaviour. Br. Poult. Sci. 21, 447-450.

Henderson, C.R., 1984. Applications of Linear Models in Animal Breeding. University of Guelph, Canada, pp. 1-423.

Hoffmeyer, I., 1969. Feather pecking in pheasants — an ethological approach to the problem. Danish Rev. Game Biol. 6, 1-36.

Hughes, B.O., 1985. Feather loss — how does it occur? In: Proceedings of the 2nd European Symposium on Poultry Welfare, Celle, Germany, 10-13 June, pp. 178-188.

Hughes, B.O., Duncan, I.J.H., 1972. The influence of strain and environmental factors upon feather pecking and cannibalism in fowls. Br. Poult. Sci. 13, 525-547.

Jensen, J., Madsen, P., 1993. A User's Guide to DMU. A Package for Analysing Multivariate Mixed Models, Danish Institute of Animal Science, Research Centre Foulum, Denmark.

Keeling, L., Wilhelson, M., 1997. Selection based on direct observations of feather pecking behaviour in adult laying hens. Proceeding of the 5th Europ. Symp. on Poultry Welfare, Wageningen, Netherlands, pp. 77-79.

Kjaer, J.B., 1995. Strain differences in feather pecking behaviour and floor laying in hens kept in aviaries. In: Proceedings of the 29th International Congress, International Soc. of Appl. Ethol., Exeter, UK, 3-5 August, Univ. Fed. for Anim. Welfare, Potters Bar, pp. 191-192.

Kjaer, J.B., Sørensen, P., 1997. Feather pecking in White Leghorn chickens — a genetic study. Br. Poult. Sci. 38, $333-341$.

Kjaer, J.B., Vestergaard, K.S., 1999. Development of feather pecking in relation to light intensity. Appl. Anim. Behav. Sci. 62, 243-254.

Liljedahl, L.E., Kolstad, N., Sørensen, P., Maijala, K., 1979. Scandinavian selection and crossbreeding experiment with laying hens. Acta Agric. Scand. 29, 273-286.

McKeegan, D.E.F., Savory, C.J., 1999. Feather eating in layer pullets and its possible role in the aetiology of feather pecking damage. Appl. Anim. Behav. Sci. 65, 73-85.

Nørgaard-Nielsen, G., Kjaer, J.B., Simonsen, H.B., 1993. Field test of two alternative egg production systems, the Hans Kier System and the BOLEG II Aviary. Research report no. 9, National Institute of Animal Science, Research Centre Foulum, pp. 1-89 (in Danish with English summary).

SAS Institute Inc., 1994. SAS/STAT User's Guide, Version 6.08. SAS Institute, Inc. Cary, NC. 
Tauson, R., Ambrosen, T., Elwinger, K., 1984. Evaluation of procedures for scoring the integument of laying hens-independent scoring of plumage condition. Acta Agric. Scand. 34, 400-408.

Wennrich, G., 1975. Studium zum Verhalten verschiedener Hybrid-Herkünfte von Haushühnern (Gallus domesticus) in Bodenintensiv-Haltung mit besonderer Berücksichtigung aggressiven Verhaltens sowie des Federpickens und des Kannibalismus, 5. Mitteilung: Verhaltensweisen des Federpickens, Arch. Geflügelk, Vol. 2, pp. 37-44. 